\title{
Predation Attempt by the Cuban Racer, Cubophis cantherigerus (Squamata: Dipsadidae) on the Cuban Giant Anole, Anolis equestris buidei (Squamata: Dactyloidae), a Threatened Endemic Subspecies
}

\author{
Tomás M. Rodríguez-Cabrera ${ }^{1}$, Javier Torres López ${ }^{2}$, Ruben Marrero ${ }^{3}$, and José A. Podio Martínez ${ }^{4}$ \\ 'Jardín Botánico de Cienfuegos, Pepito Tey, Cienfuegos, CP 59290, Cuba (tomasmichel.rodriguez@gmail.com) \\ 2Departamento de Biología Animal y Humana, Facultad de Biología, Universidad de la Habana, La Habana, CP 10400, Cuba (javiertorres@fbio.uh.cu) \\ ${ }^{3}$ División de Zoología de Vertebrados, Instituto de Ecología y Sistemática, La Habana, CP 11900, Cuba (rubens@ecologia.cu) \\ ${ }^{4}$ Servicios Ambientales de Matanzas, Varadero, Cárdenas, Matanzas, CP 10800, Cuba (jeseangel.podio@nauta.cu)
}

Snakes swallow their prey whole, so gape limits the size of $\checkmark$ the prey they can consume (e.g., Rodríguez-Robles et al. 1999; Vincent et al. 2006). Nevertheless, most snakes are able to capture, subdue, and kill large potential prey, but in some instances such an animal is too large for the snake and cannot be swallowed (e.g., Caramaschi and Niemeyer 2012; Fong et al. 2013; Vargas-Salinas and Aponte-Gutierrez 2013; Torres et al. 2014b). On other occasions, the potential prey can be swallowed but exceeds the snake's stomach capacity and is later regurgitated (with the consequent waste of energy) or the snake might even die (e.g., Caramaschi and Niemeyer 2012). Regardless, the eventual result is unsuccessful or failed predation. This phenomenon has been reported twice in Cuban snakes, and both cases involved the Cuban Giant Trope, Tropidophis melanurus (Tropidophiidae; Fong et al. 2013; Torres et al. 2014). However, few cases of "failed predation" have been reported in other than constricting snakes (e.g., Vargas-Salinas and Aponte-Gutierrez 2013). Herein we report "failed predation" by a Cuban Racer, Cubophis cantherigerus cantherigerus (Dipsadidae), on a Cuban Giant Anole, Anolis equestris buidei (Dactyloidae; Fig. 1). This is the first report of "failed predation" by a colubroid snake in the West Indies, and the first report of a snake attempting to prey on an anole of the crown-giant ecomorph in Cuba.

At 1250 h on 7 April 2004, an adult Cubophis c. cantherigerus (ca. $750 \mathrm{~mm}$ SVL, $37 \mathrm{~mm}$ head length) and an adult female Anolis equestris buidei (ca. $165 \mathrm{~mm}$ SVL, 51 $\mathrm{mm}$ head length) fell from the thatched roof of a small rustic wooden gazebo (Fig. 2) in the protected area "Varahicacos" $\left(23^{\circ} 11^{\prime} 39^{\prime \prime} \mathrm{N},-81^{\circ} 09^{\prime} 11^{\prime \prime} \mathrm{W}\right.$; WGS 84) on the Hicacos Peninsula (Fig. 3), Cárdenas, Matanzas Province, Cuba.
When they hit the ground, the snake had bitten the right forearm of the lizard (Fig. 4A). The snake rapidly laid one coil around the pelvic region of the lizard (Fig. 4B) and remained in that position for about $45 \mathrm{sec}$. During this time, the snake tried repeatedly to swallow the forearm of the lizard until it reached the scapular region, after which it released the coil (Fig. 4C). The snake maintained the bite for $2 \mathrm{~min}$ and $25 \mathrm{sec}$, during which it frequently readjusted its jaws. Subsequently, the snake released the lizard, which remained motionless, with eyes closed, and with a drab olive-yellow coloration (Figs. 4D-F). The snake immediately searched for the head of the lizard and commenced swallowing (Fig. 4D). After about a minute and a half, the snake ceased trying to swallow the lizard, but remained alongside it for about four

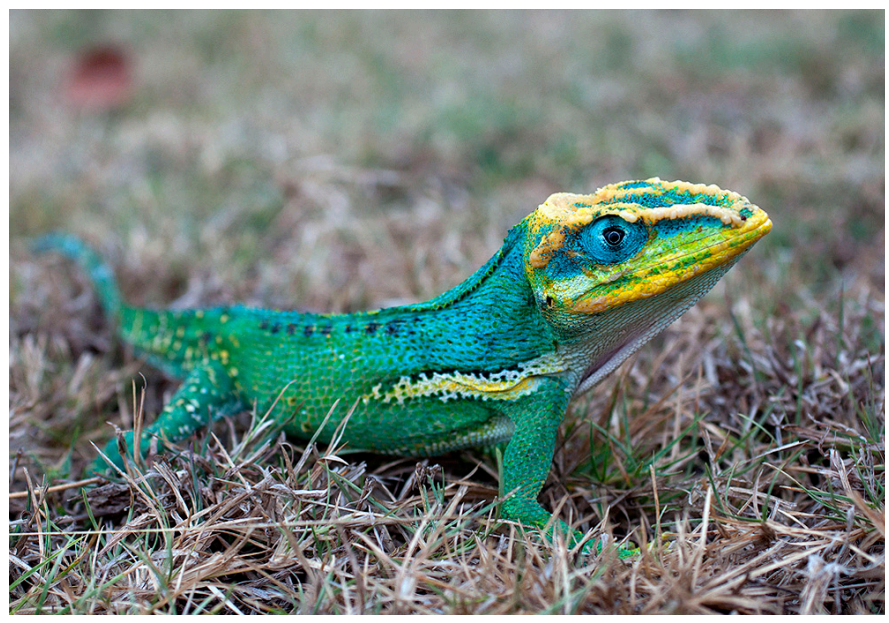

Fig. 1. An adult male Cuban Giant Anole (Anolis equestris buidei) from the protected area "Varahicacos," Matanzas Province, Cuba. Photograph by Raimundo López-Silvero. 


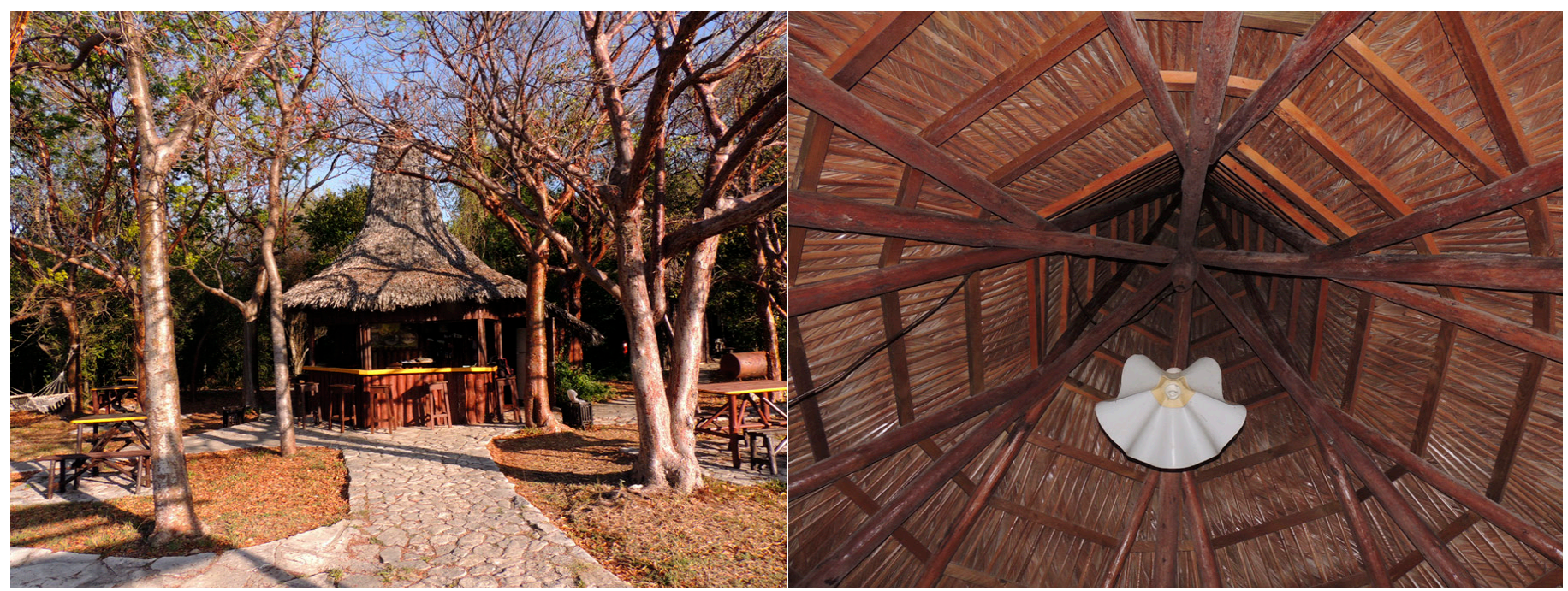

Fig. 2. Rustic wooden gazebo (A) at the protected area "Varahicacos" where we observed the predation attempt. (B) Inside view of the roof where the lizard was presumably resting. Photographs by Tomás M. Rodríguez-Cabrera.

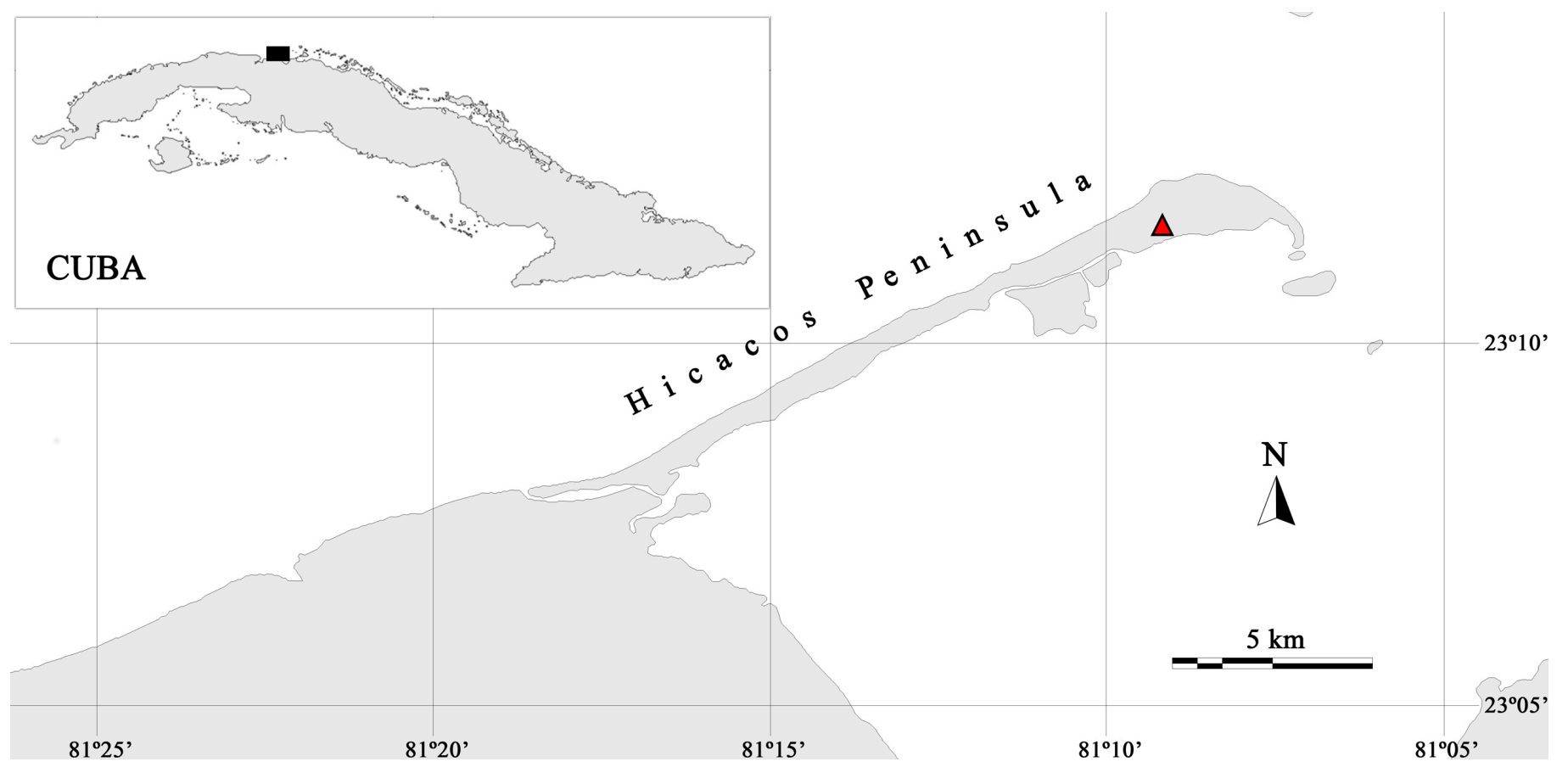

Fig. 3. Map of the Hicacos Peninsula depicting the location (triangle) where we observed the predation attempt by a Cuban Racer (Cubophis cantherigerus cantherigerus) on a Cuban Giant Anole (Anolis equestris buidei).

more minutes, opening its mouth and readjusting the jaws (Fig. 4E). The snake then bit the lizard before abandoning it (Fig. 4F). We examined the lizard immediately and found that it had died. Whether the snake abandoned the lizard because of an insufficient gape size, because of the photographer's proximity, or some combination of both is uncertain.

"True predators" (sensu Begon et al. 2006) kill and consume their prey more or less immediately after attacking it, which ensures the flow of energy and matter from one trophic level to the next. Thus, an instance in which an animal captures and kills another without ingestion and the subsequent energetic reward should be classified as "unsuccessful or failed predation." Unsuccessful predation has two potential outcomes for the prey. It might be captured and killed or it is captured but not killed by the potential predator. In the first case, the potential prey can be consumed by detritivores and enter the decomposer chain directly (see Begon et al. 2006). In the second instance, the potential prey remains alive and no alteration in the flux of energy occurs except for the energy wasted by both individuals involved in the predation attempt.

West Indian anoles of the crown-giant ecomorph are among the largest species in the genus Anolis, with snout-vent lengths sometimes exceeding $190 \mathrm{~mm}$ (e.g., Losos 2009). This ecomorph comprises 12 species distributed in Cuba 
(6), Hispaniola (3), Jamaica (1), and the Greater Puerto Rico Bank (2; e.g., Henderson and Powell 2009; Losos 2009; Powell and Henderson 2012). In addition to large size, some of these anoles are very aggressive and have a powerful bite (see Henderson and Powell 2009 for a review). Nonetheless, even this considerable aggression does not deter some predators,

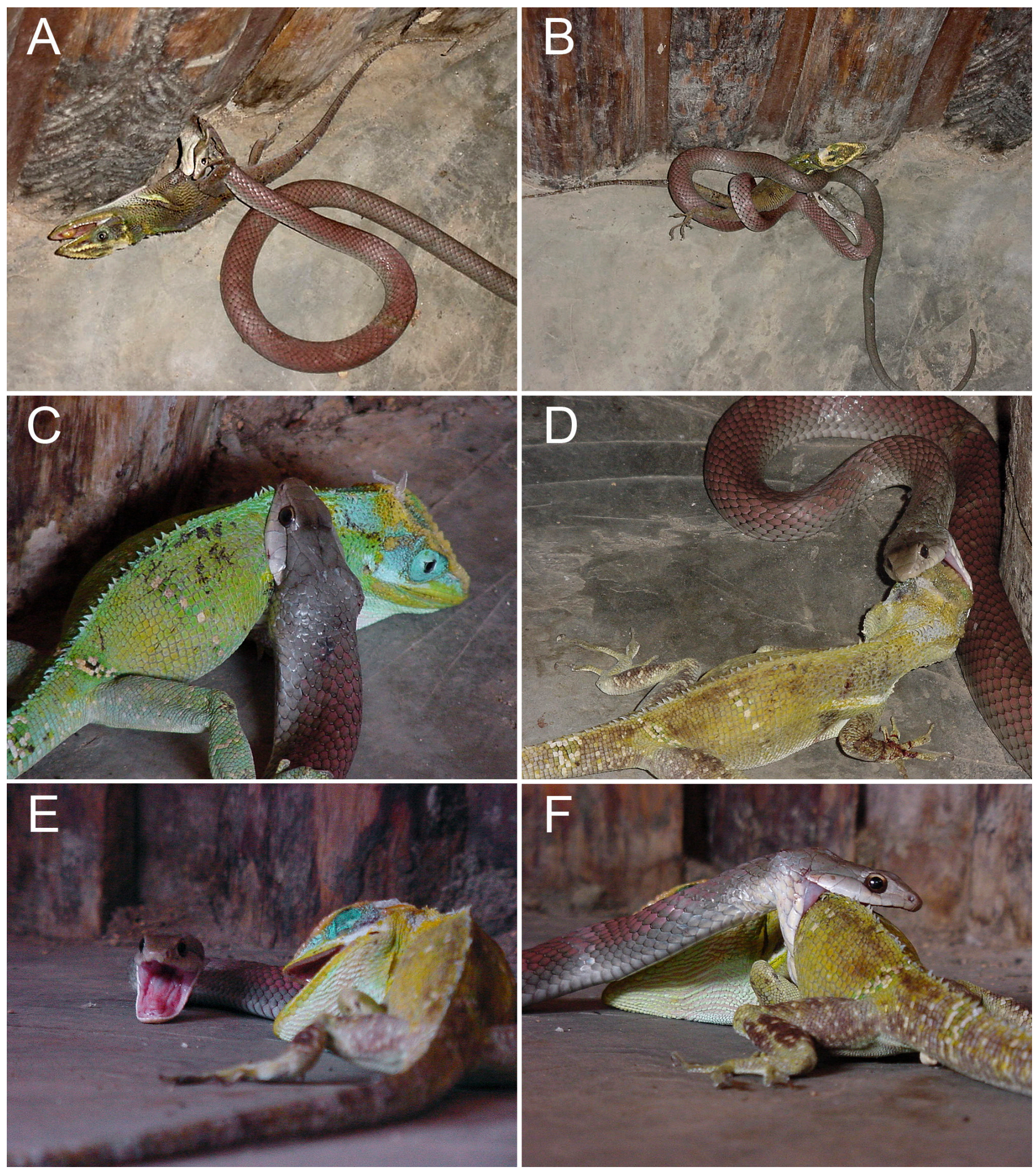

Fig. 4. Sequence of photographs of failed predation by a Cuban Racer (Cubophis cantherigerus cantherigerus) on a Cuban Giant Anole (Anolis equestris buidei): (A) Immediately after falling to the ground, (B) the snake coils around the lizard, (C) the snake swallowing the right forelimb and biting the scapular region of the lizard, (D) the snake trying to swallow the lizard by its head, (E) the snake readjusting its jaws adjacent to the motionless lizard, and (F) the snake biting the lizard before abandoning it. Photographs by Jose A. Podio Martínez. 

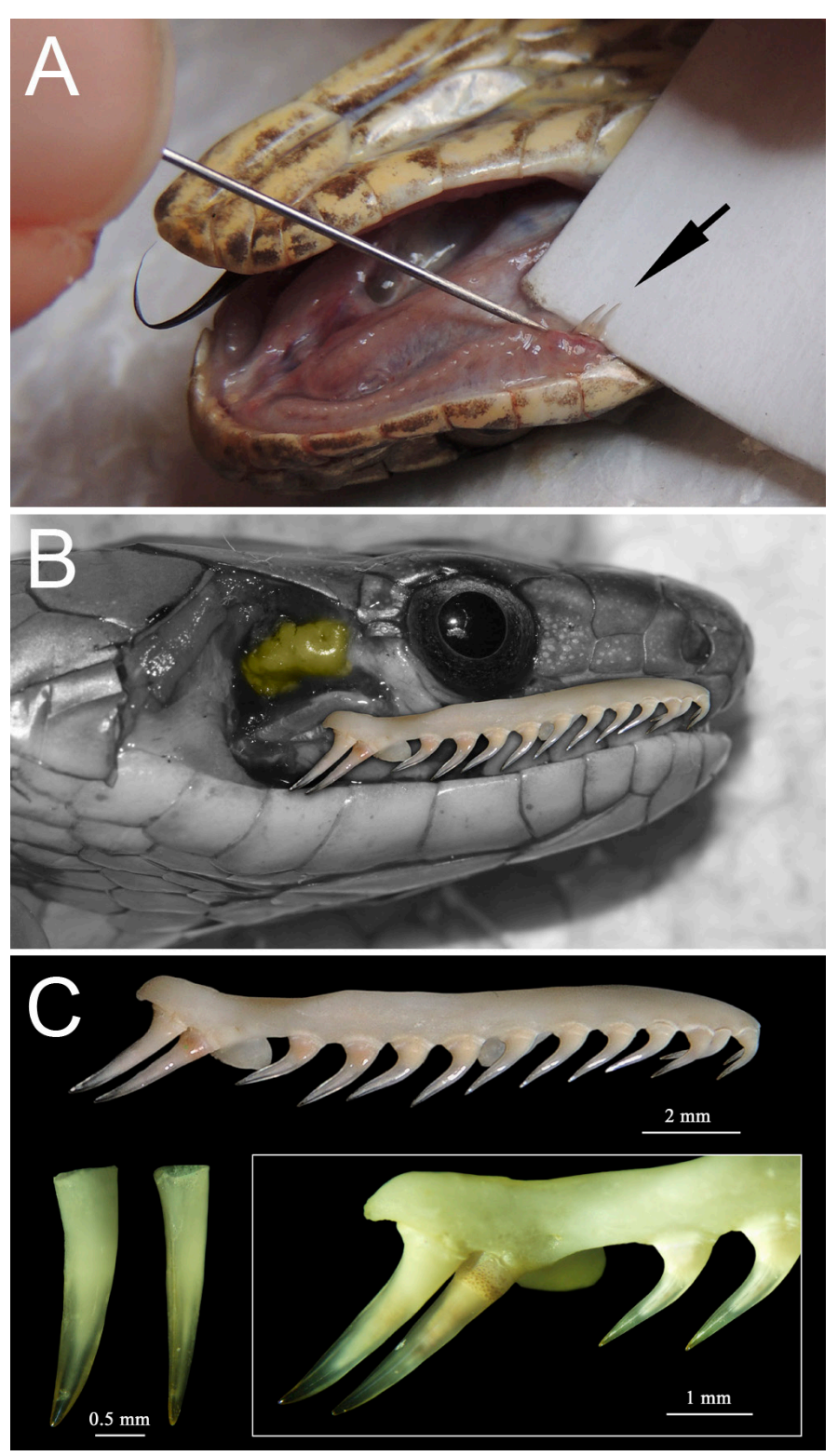

Fig. 5. Sequence showing the opistoglyphous condition of the Cuban Racer (Cubophis cantherigerus): (A) Enlarged posterior teeth (arrow) in a live individual; (B) lateral view of the head with skin and muscles removed, showing the maxilla (superimposed); and (C) details of the maxilla. Photographs by Ruben Marrero (A, B) and Tomás M. RodríguezCabrera (C).

and several species are known to consume giant anoles. These include snakes (Borikenophis, Chilabothrus, Magliophis), birds (Buteo, Coccyzus, Crotophaga, Falco, Margarops, Quiscalus, Turdus, Tyto), and mammals (Herpestes, Homo, Rattus; see Henderson and Powell 2009 for a review). However, the only confirmed predators in Cuba are birds (Coccyzus merlini, Falco sparverius, and Turdus plumbeus) and only the Cuban Giant Anole (Anolis equestris) is recorded as prey (see Henderson and Powell 2009 for a review).

Envenomation could be responsible for the death of the lizard reported herein, especially after a bite sustained for several minutes. The Cuban Racer is an opistoglyphous snake (i.e., with enlarged posterior maxillary fangs; Neill 1954; Jaume and Garrido 1980; this paper; Fig. 5). The venom is not lethal to humans, but it can occasionally produce inflammation, flushing, pain, and fever (Neill 1954; Jaume and Garrido 1980). For actual prey, it might facilitate submission (Henderson and Sajdak 1996) or even initiate digestion. However, no research has examined the toxic effects of the Cuban Racer's venom in different kinds of prey, nor has its Duvernoy's gland been studied. This is in sharp contrast with the Puerto Rican Racer (Borikenophis portoricensis), in which both the venom and the envenomation apparatus has been described in some detail (Rodríguez-Robles 1992; RodríguezRobles and Thomas 1992; Rodríguez-Robles and Leal 1993; Weldon and Mackessy 2010).

The Cuban Giant Anole, which comprises 11 subspecies, is widely distributed in the Cuban Archipelago (Schwartz and Garrido 1972; Garrido 1975, 1981; Garrido et al. 2001) and has been introduced into Florida and Oahu, Hawaii (e.g., Brach 1974; Dalrymple 1980; Henderson and Powell 2009). Anolis equestris buidei Schwartz and Garrido 1972 (maximum SVL $176 \mathrm{~mm}$ in males and $148 \mathrm{~mm}$ in females) occurs exclusively on the Hicacos Peninsula, the northernmost point of mainland Matanzas Province (Schwartz and Garrido 1972, 1981). This subspecies was considered "Vulnerable" by Rodríguez Schettino (1999), but its restricted distribution (less than $15 \mathrm{~km}^{2}$ ) and current threats (i.e., reduction and fragmentation of suitable habitats because of increased development for tourism; see Torres et al. 2014b) might warrant classification as "Critically Endangered." Predation is natural, but can have harmful effects on declining populations when the predation rate exceeds the recovery rate of prey populations (see Begon et al. 2006). Consequently, understanding all real and potential threats affecting this lizard, whether natural or anthropogenic, is crucial for its management and long-term conservation.

\section{Acknowledgements}

We acknowledge Rosario Domínguez, Raimundo LópezSilvero, and Anaisa Cajigas Gandia for field assistance and for helping with photographs. We also thank Ansel Fong for providing literature. Finally, the administration of the protected area "Varahicacos", particularly its director Daniel Fajardo, helped with technical and logistical support.

\section{Literature Cited}

Begon, M., C.R. Townsend, and J.L. Harper. 2006. Ecology. From Individuals to Ecosystems. 4th ed. Blackwell Publishing, Malden, Massachusetts.

Brach, V. 1976. Habits and food of Anolis equestris in Florida. Copeia 1976: 187189.

Caramaschi, U. and H. Niemeyer. 2012. Unsuccessful predation of Elapomorphus quinquelineatus (Serpentes: Colubridae) on Amphisbaena microcephala (Amphisbaenia: Amphisbaenidae). Herpetology Notes 5: 429-430.

Dalrymple, G.H. 1980. Comments on the density and diet of a giant anole Anolis equestris. Journal of Herpetology 14: 412-415. 
Fong G., A., I. Bignotte Giró, and K. Maure García. 2013. Unsuccessful predation on the toad Peltophryne peltocephala (Bufonidae) by the Cuban snake Tropidophis melanurus (Tropidophiidae). Herpetology Notes 6: 73-75.

Garrido, O.H. 1975. Nuevos reptiles del Archipiélago Cubano. Poeyana 141: 1-58.

Garrido, O.H. 1981. Nueva subespecie de Anolis equestris (Sauria: Iguanidae) para Cuba, con comentarios sobre la distribución y afinidades de otras poblaciones del complejo. Poeyana 232: 1-15.

Garrido, O.H., L.V. Moreno, and A.R. Estrada. 2001. Subespecies nuevas de reptiles del complejo Anolis equestris (Lacertilia: Iguanidae) para los cayos Las Brujas, Coco y Sabinal, Archipiélago de Sabana-Camagüey, Cuba. Solenodon 1: 55-65.

Henderson, R.W. and R. Powell. 2009. Natural History of West Indian Amphibians and Reptiles. University Press of Florida, Gainesville.

Henderson, R.W. and R.A. Sajdak. 1996. Diets of West Indian racers (Colubridae: Alsophis): Composition and biogeographic implications, pp. 227-338. In: R. Powell and R.W. Henderson (eds.), Contributions to West Indian Herpetology: A Tribute to Albert Schwartz. Society for the Study of Amphibians and Reptiles. Contributions to Herpetology, volume 12. Ithaca, New York.

Jaume, M.L. and O.H. Garrido. 1980. Notas sobre mordidas de jubo Alsophis (Serpentes: Colubridae). Miscelánea Zoológica 11: 2-3.

Neill, W.T. 1954. Evidence of venom in snakes of the genera Alsophis and Rhadinea. Copeia 1954: 59.

Losos, J.B. 2009. Lizards in an Evolutionary Tree: Ecology and Adaptive Radiation of Anoles. University of California Press, Berkeley.

Powell, R. and R.W. Henderson (eds.). 2012. Island lists of West Indian amphibians and reptiles. Bulletin of the Florida Museum of Natural History 51: 85-166.

Rodríguez Schettino, L. 1999. Introduction, pp. 1-16. In: L. Rodríguez Schettino (ed.), The Iguanid Lizards of Cuba. University Press of Florida, Gainesville.
Rodríguez-Robles, J.A. 1992. Notes on the feeding behavior of the Puerto Rican Racer, Alsophis portoricensis (Serpentes: Colubridae). Journal of Herpetology 26: 100-102.

Rodríguez-Robles, J.A. and M. Leal. 1993. Effects of prey type on the feeding behavior of Alsophis portoricensis (Serpentes: Colubridae). Journal of Herpetology 27: 163-168.

Rodríguez-Robles, J.A. and R. Thomas. 1992. Venom function in the Puerto Rican Racer, Alsophis portoricensis (Serpentes: Colubridae). Copeia 1992: 62-68.

Rodríguez-Robles, J.[A.], C.J. Bell, and H.W. Greene. 1999. Gape size and evolution of diet in snakes: Feeding ecology of erycine boas. Journal of Zoology 248: 49-58.

Schwartz, A. and O.H. Garrido. 1972. The lizards of the Anolis equestris complex in Cuba. Studies on the Fauna of Curaçao and Other Caribbean Islands 39: 1-86.

Torres, J., C. Pérez-Penichet, and O. Torres. 2014a. Predation attempt by Tropidophis melanurus (Serpentes, Tropidophiidae) on Anolis porcus (Sauria, Dactyloidae). Herpetology Notes 7: 525-526.

Torres, J., O. Torres, and R. Marrero. 2014b. Herpetofauna of Cayo Romero (North-Western Cuba), a new locality for Aristelliger reyesi (Sauria, Sphaerodactylidae). Herpetology Notes 7: 707-712.

Vargas-Salinas, F. and A. Aponte-Gutierrez. 2013. A race for survivorship: Failed predation on the toad Rhinella humboldti (Gallardo, 1965) by the Cat-eyed Snake Leptodeira septentrionalis (Kennicott, 1859). Herpetology Notes 6: 189-191.

Vincent, S.E., P.D. Dang, A. Herrel, and N.J. Kley. 2006. Morphological integration and adaptation in the snake feeding system: A comparative phylogenetic study. Journal of Evolutionary Biology 19: 1545-1554.

Weldon, C.L. and S.P. Mackessy. 2010. Biological and proteomic analysis of venom from the Puerto Rican Racer (Alsophis portoricensis: Dipsadidae). Toxicon 55: 558-569. 